\title{
The nestling diet of fairy pitta Pitta nympha on Jeju Island, Korea
}

\author{
Eun-Mi Kim ${ }^{1}$, Chan-Ryul Park ${ }^{1,2^{*}}$, Chang-Wan Kang ${ }^{3}$, Se-Jae Kim ${ }^{4}$ \\ ${ }^{1}$ Warm-temperate Forest Research Center, Korea Forest Research Institute, Seogwipo, Korea \\ ${ }^{2}$ Division of Forest Ecology, Korea Forest Research Institute, Seoul, Korea; ${ }^{*}$ Corresponding Author: park@forest.go.kr \\ ${ }^{3}$ The Korea Association for Bird Protection Jeju Branch, Seogwipo, Korea \\ ${ }^{4}$ Department of Biology, Jeju National University, Jeju, Korea
}

Received 1 July 2012; revised 4 August 2012; accepted 29 August 2012

\section{ABSTRACT}

The nestling diet of the Fairy Pitta (Pitta nympha) was studied by videotaping during breeding period in Jeju Island, 2009. Earthworms of several species were the most common food resources for nestlings, averaging $82 \%$ of all items, followed by $4 \%$ of Homoptera larvae. The remaining was only rarely recorded, including Lepidopteran larvae and adults, slugs, spiders, beetle adults and larvae (Coleoptera) and grasshoppers. Adults provided the number of preys ranging from 1 to 7 items to chicks per one visit. The average value of prey number per visit was 3.0 (SD = 1.38). The estimated average length of prey was $5.7 \mathrm{~cm}(S D=2.85)$, and $96 \%$ of the food items were smaller than $10 \mathrm{~cm}$. The staying time for feeding in an early stage was longer than other stages. Provision rate at a forenoon (mean $\pm \mathrm{SD}, 14.7 \pm 4.92)$ and an afternoon time (15.8 \pm 5.30) was not significantly higher than that of noon time $(11.7 \pm 4.49)$. These results provide basic information for conservation action of international endangered species of this species.

Keywords: Earthworm; Prey Availability; Prey Size; Rainfalls; Videotaping

\section{INTRODUCTION}

The Fairy Pitta (Pitta nympha) is migratory, breeds in forest habitats of Taiwan, Japan, southeastern China, and Korea and winter mainly on the Borneo [1]. Its population is suspected to be rapidly declining owing to deforestation in its breeding ranges, principally for agriculture and timber, locally compounded by trapping for the cage bird trade. It is listed as being in a vulnerable C1 status according to IUCN (International Union for Conservation of Nature) criteria [2]. The birds are highly susceptible and inhabit a dark, humid, and dense forest which is difficult for person to approach. A detection of the Fairy Pitta is difficult, then we don't understand its lifestyle and ecology. For conservation of this threatened species, ecological studies on its breeding habitat requirements are essential [2]. In Korea, Fairy Pitta was recorded at Geoje Island, Bogil Island and Daejeon, Jeju Island and most brood in Jeju Island located at the southern part of country. It arrived in late May for breeding and adults engage in singing. Adults lay the 1st eggs in early June. The clutch size ranges from 3 to 6 , but 3 or 6 are rare. Most young birds are observed from late June to early August. This species was mainly found around large and small valley and evergreen forests [3]. Only we had few survey records on this bird conducted at the avifauna research in Korea. Before 1945, a few Japanese scholars recorded its observation at the southern slope of Mt.Halla based on the collection and the song near the Gwaneumsa temple. At 1950s, we had only one record in the book which American Austin had recorded about Jejulived 5 birds. In 1960s, Korean scholars started the study about Fairy Pitta and recorded that the bird inhabited from $1200 \mathrm{~m}$ to $1600 \mathrm{~m}$ above sea level around Youngsilgiam ridge [4]. Reference [5] reported that this species brood around 1000 to $1200 \mathrm{~m}$ in the altitude. In 1980s, some local scholars reported that it was observed at a Suak and a Donnaeko valley, ranging from $500 \mathrm{~m}$ to $600 \mathrm{~m}$ in northern part of Mt.Halla. Reference [6] reported that this species distributed from $100 \mathrm{~m}$ to $800 \mathrm{~m}$ and the main distribution area from $400 \mathrm{~m}$ to $500 \mathrm{~m}$ at Jeju Island, Korea. The breeding success of this bird probably depends on the availability of suitable nestling habitat provide adequate prey for nestlings [7]. In this study, we collected quantitative data on the nestling diet of the Fairy Pitta.

\section{STUDY AREA AND METHODS}

\subsection{Study Area}

This study was conducted at Jeju Experimental Forests (JEFs), Seogwipo city in southern slope of Mt.Halla, Jeju 
Island, Korea $\left(126^{\circ} 39^{\prime} \mathrm{E}, 33^{\circ} 21^{\prime} \mathrm{N}\right)$ from June to July, 2009. This area is about 1191 ha with elevations ranging from 300 to $750 \mathrm{~m}$, and certificated forest for forest management by FSC (Forest Stewardship Council). Climate is subtropics, warm-temperate and temperate zone. Annual precipitation is about $3000 \mathrm{~mm}$. Major forest types are evergreen forests, such as Quercus acuta, Castanopsis sieboldii, Neolitsea aciculata and N. sericea and deciduous forests such as Carpinus laxiflora, Quercus serrata and Styrax japonica. Others are Cedar plantation forests. Soil depth is relatively deep and has developed well in organic layer and stratum [8].

\subsection{Video Recording}

In study area, the Fairy Pitta arrived in late May and began actively singing. Most nests were built on the big rock at a steep slope, with staking the forks of trees like a big rugby ball. We selected two nests and recorded nesting activities with a video recorder (SONY HCR-H1) and saved the files at the digital video recorder (ARGUS Network DVR XAD-401). We set up the instrument and recorded images during two months with an unmanned video device to minimize the potential disturbance and to avoid the breeding parents of Fairy Pitta abandoning the nests. The equipment operates during night and day to catch what parents to do, when to start and finish feeding in night. We did not touch the nest, any juveniles and parents during recording periods. Also, we did not identify the any predator attacking nests. So, we did not affect any breeding process in getting the breeding images by setup the video instruments.

\subsection{Video Analysis}

We summed the data of two nests and analyzed the number of visit by parents, and number of prey per one visit, and the prey size at the $2 \mathrm{~cm}$ intervals (2, 4, 6, 8, 10, over $10 \mathrm{~cm}$ ) according to the bill size of parents. Bill sizes were obtained by previous results [3]. We analyzed the life stage of prey as larval or adult and classified the prey type into earthworms, Homoptera, Lepidoptera, Coleoptera, Orthoptera, slugs and spiders. The length of the prey was determined by at the interval of $2 \mathrm{~cm}$ comparing with the length of parents' bill.

\subsection{Statistical Analysis}

Parents transferred prey from 500 to 2000 hrs, so we divided total timed into three times like forenoon (500 1000), noon (1000 - 1600), and afternoon (1600 - 2000) due to the light intensity difference among three times in dense forests. Fairy pitta do search prey at the forest floor, so the light condition will affect the prey detectability. We applied the Mann-Whitney U-test [9] with R statistic program to understand the difference of number of prey among times [10].

\section{RESULTS}

\subsection{Diet Composition}

Four nestlings departed the nest successfully at two nests respectively. The nestlings left their nests on the 13th day after hatching at two nests. In total, 372 feeding visits were recorded during the study period. Parents of fairy pitta visited 274 times with prey items, and we identified and recorded the contents of 826 prey items. Earthworms of several species were the most common prey items for nestlings, averaging $81.7 \%$ of all preys. Homopteran larvae were the second largest identifiable food item, comprising $4 \%$ of prey items. The others were only rarely recorded, including Lepidopteran larvae and adults, slugs, spiders, beetle adults and larvae (Coleoptera) and grasshoppers (Orthoptera, Figure 1).

\subsection{Number of Prey Items per Visit}

Parents brought the number of prey ranging from 1 to 7 items per visit, but they delivered the prey at the average number of $3.0 \pm 1.38(n=274)$ items per one visit. Visit numbers ranging from 2 to 4 composed of $67 \%$ of the feeding visit (Figure 2(a)). Number of delivered preys was affected by food types, there was a significant difference of percentage distribution of number of delivered preys between earthworms $(3.0 \pm 1.33 ; n=224)$ and the others $(1.4 \pm 0.64, \mathrm{n}=111$, Mann-Whitney $\mathrm{U}$ test, $\mathrm{Z}$ $=-10.415, \mathrm{p}<0.001$, Figure 2(b)). Parents delivered diverse numbers of earthworms to the nestlings, but they did no more than three preys of the others.

\subsection{Number of Prey Items per Visit}

Average length of delivered prey was $5.7 \pm 2.85 \mathrm{~cm}$ (n = 826), and $96 \%$ of the food items were smaller than $10 \mathrm{~cm}$

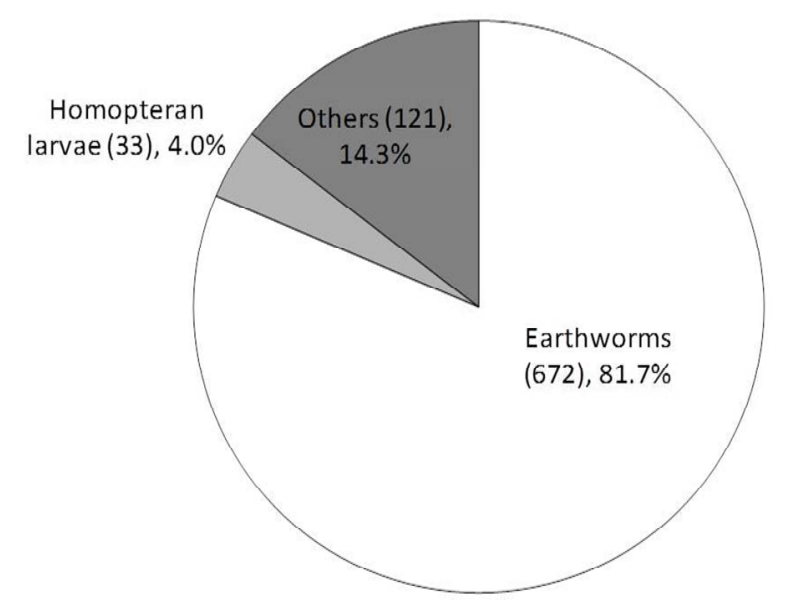

Figure 1. Diet composition of the delivered prey based on individual percentage by parents of fairy pitta. 

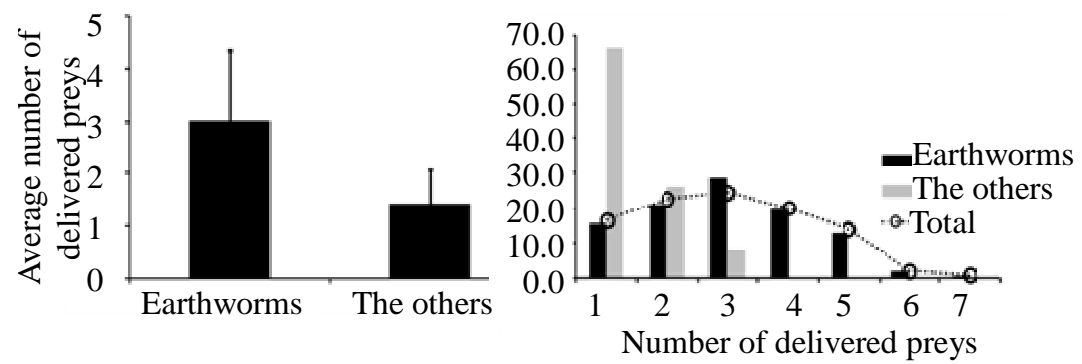

Figure 2. Average number (a) and percentage distribution (b) of delivered preys of earthworms $(n=224)$ and the others $(n=111)$, and percentage distribution (b) of total delivered preys $(\mathrm{n}=274)$.

(Figure 3(a)), but a few large items were observed. The average length of earthworms $(6.8 \pm 2.39 \mathrm{~cm}, \mathrm{n}=670)$ was significantly longer than the others $(2.2 \pm 1.11 \mathrm{~cm}$, Mann-Whitney U test, $\mathrm{Z}=-17.929, \mathrm{p}<0.001$, Figure 3(b)). The longest prey of earthworm was estimated at 13 $\mathrm{cm}$ in length. Earthworms only dominated the prey size longer than $10 \mathrm{~cm}$. So, Parents utilized the diverse size of earthworms and small-sized prey of the others.

\subsection{Hourly Difference of Prey Delivered in a Day}

We compared the delivery rates of prey among three time zones in a day during nestling periods. Provision rate at a forenoon $(14.7 \pm 4.92)$ and an afternoon zone $(15.8 \pm 5.30)$ was significantly higher than lunchtime zone $(11.7 \pm 4.49$, Mann-Whitney $\mathrm{U}$ test, $\mathrm{Z}=-1.298$ (forenoon and lunchtime zone, $\mathrm{p}<0.05$ ), $\mathrm{Z}=-1.695$ (afternoon and lunchtime zone, $\mathrm{p}<0.05$ ), Figure 4).

\subsection{Staying Time of Parents at Nest During Nestling Period}

The staying time of parents in an early stage (196.4 minutes/day $\pm 24.56, \mathrm{n}=3$ ) was far longer than other stages of middle stage (30.4 minutes/day $\pm 37.17, \mathrm{n}=3$, $\mathrm{p}=0.05$ ) and late stage (6.6 minutes/day $\pm 2.2, \mathrm{n}=5, \mathrm{p}=$ $0.02)$. There was no significant difference of staying time between middle and late stage ( $p=0.07$, Figure 5$)$. So, parents did spend about three hours in caring nestlings and defending nests against predators during early breeding stage.

\section{DISCUSSION}

\subsection{Diet Composition and Prey Availability}

Earthworms dominated the $82 \%$ of diet composition of nestlings of Fairy Pitta (Figure 1). Reference [7] reported the $73 \%$ of diet ratio at Taiwan region. Earthworms can affect the breeding success of international endangered species Fairy Pitta. Earthworms do survive with epidermis respiration under grounds, and the body weight of earthworms consists of $75 \%-90 \%$ of water [11], so rainfall amount and season can affect the breed- ing success at warm-temperate forests. The habitat of earthworms are known to be related with the soil water condition [12], they have a difficulty in surviving at the condition over $35 \%$ of water contents of soil. Therefore, earthworms emerge from undergrounds against filling with water at the microhabitat of ground tunnel in rainy days. Fairy pitta can sustain high detectability of earthworms in rainy days. Reference [8] reported the annual precipitation amounts of near $3000 \mathrm{~mm}$ per year with automatic logging system since 2007. Dense and mature forests of Jeju experimental forests can affect the provision of earthworms $[11,12]$ and the breeding success of the Fairy Pitta. Therefore, rainfall factors such as heavy rainfall days over $80 \mathrm{~mm}$ per day from early June to early August can affect the prey availability of Fairy Pitta at JEFs. Comparing with the number of delivered prey between earthworms and the others' invertebrates, Fairy pittas showed high using ratio of earthworms as prey resource, however, they transferred not only earthworms and but also other invertebrates. In the percentage distribution, Invertebrates prey ranging under $4 \mathrm{~cm}$ occupied the higher ratio and numbers than earthworms did (Figure 3). It suggests the possibility of diverse use of prey type in the size distribution. Endangered species do show the specialist at the use of food resources and this specialty can affect the high extinction rate of species extermination [13], in this viewpoint Fairy Pitta seems to have a narrow diversity in the prey use. Except earthworms invertebrates like Lepidopteran juveniles and larvae and Coleoptera, Spiders and Slugs composed the main prey resources for nestling of Fairy Pitta (Figure 1). Invertebrates showed high observation of species richness and density from early June to early August at JEFs [14], so Fairy Pitta did match the breeding season at high biomass periods of invertebrates.

\subsection{Change of Caring Time for Nestlings}

Parents showed the significant high staying time at early stages than two stages they did (Figure 3). We observed that parents did care nestlings for four days after hatching, it can be ascribed to the maintenance of air temperature against severe weather condition at rainy 


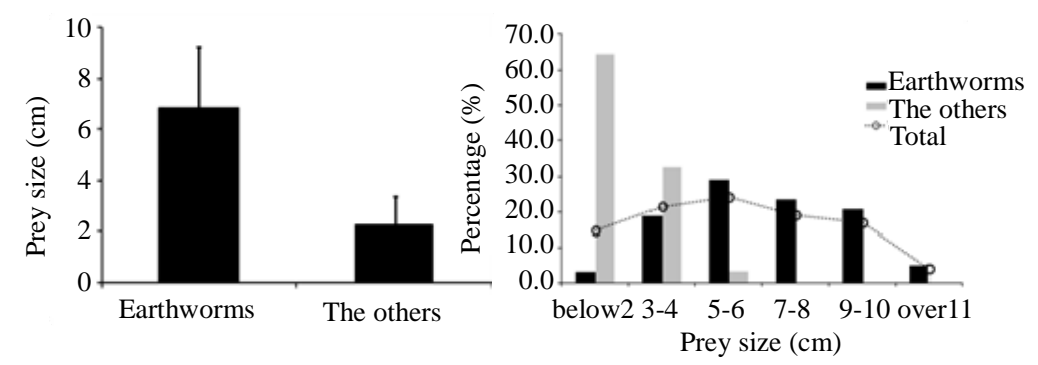

Figure 3. Average length (a) and percentage distribution (b) of prey sizes of earthworms $(n=670)$ and the others $(n=156)$, and percentage distribution of prey size delivered by parents Fairy Pitta $(n=826)$.

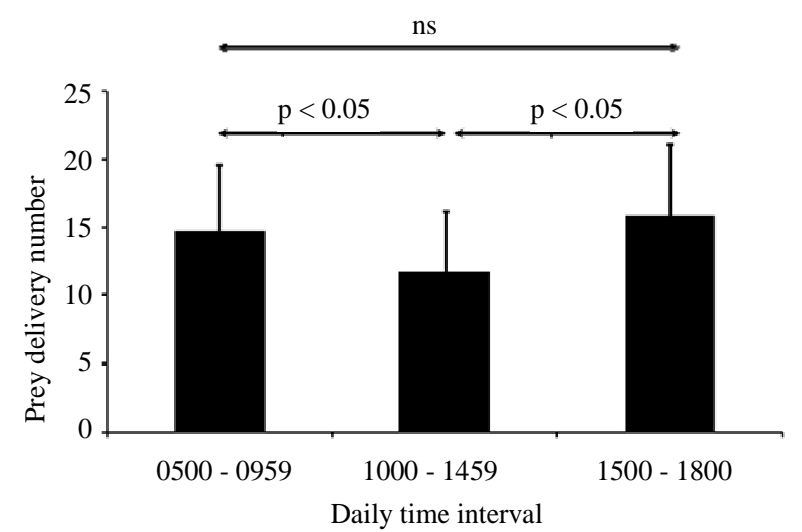

Figure 4. Comparison of daily prey delivery among forenoon $(n=103)$, noon $(n=94)$ and afternoon $(n=111)$ time intervals.

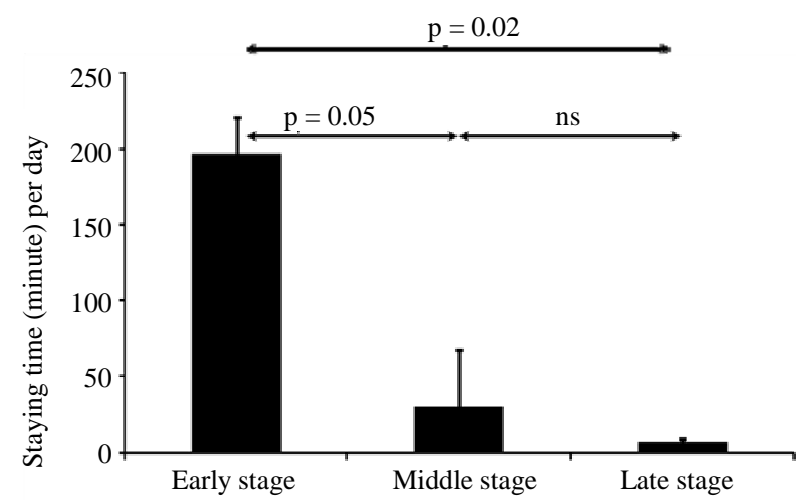

Figure 5. Comparison of staying time at nest per day in three breeding stages.

season, not to provide the prey to nestlings. In the case of forest passerine birds, number of nest visits is related with the amounts of prey availability [16-18], however Fairy pitta spent more time to caring at early stages. We wonder if parents have a defense strategy against predator, however it is important to note the high ratio of caring time at early stages in this study area.

\subsection{Comparison with the Habitat of Fairy Pitta in Taiwan}

In Taiwan, parents of Fairy pitta visited about seventy times per day and they showed average 1.8 number per visit in Taiwan [7], in Korea, however they visited about forty times (Figure 4) and they delivered about four preys per visit. So, there is a possibility of difference between two regions, high visit with low prey-load in Taiwan and high prey-load with low visit in Korea. These phenomenon can be ascribed to the forest type (warm-temperate forests in Korea and sub-tropical forests in Taiwan) and biodiversity (relatively high and intensively networked in Taiwan), that is prey availability and predator risk. In the viewpoint of predation risk, there will be a high predation risk due to high biodiversity of predators in Taiwan. In Taiwan, Reference [7] reported the predators of Fairty pitta as follows; mammals (Macaque, Mongoose and Civets), snakes, birds and ants [7]. However, we can suggest cat snake (Elaphe dione) and Jungle crow (Corvus macrorhynchos) as predators.

Meanwhile, there was no prey belonging to vertebrates at this area, however vertebrates including frogs, lizards, snakes and rodents (Soricidae) dominated the $4 \%$ of prey at Taiwan area [7]. There was a presence report on the amphibians, reptiles and small rodents at JEFs, however those vertebrates were mainly observed at the open grassland, and their occurrence rate was not so abundant [15]. Also, it seems that Fairy Pitta should spend more cost to catch and handle these vertebrate's preys. Comparing with the habitat condition of Taiwan, Fairy pitta may shift their main prey of invertebrates to vertebrates. Actually there was one time observation records (Kim EunMi, personal communication) on the delivering the lizards to the nests of Fairy Pitta in 2006.

\subsection{Threatening Factors to the Fairy Pitta at JEFs}

As prey resources, earthworms can have a good merit to nestlings because earthworms can be easily fragmented and a high energy sources to nestlings. Passerine birds can digest the large-sized prey (over $4 \mathrm{~cm}$ ) after one week since hatching [19-21], so thrushes and some ground foragers have a preference to earthworms. In fu- 
ture, the preference mechanisms to earthworms should be addressed to conserve the population of Fairy pitta. In the other viewpoint, earthworms' density is negatively related with the ground trampling [22], so intensity of eco-tourisms and logging area can be detrimental to the breeding success of Fairy pitta. Also, it was known that over fifty-year forests can sustain high density of earthworms [22], so the conservation of over fifty-year forests can be more effective way to conserve the internationally threatened species. Volcanic bedrocks of study areas can have a limit to maintain the high depth of litter layer and soil humidity for the earthworms' habitat, so it is essential to conserve the interaction between soil and litter layer at JEFs.

\section{ACKNOWLEDGEMENTS}

This study was financially supported by forest science project grant No. 500-20080086 of Korea Forest Service.

\section{REFERENCES}

[1] Lambert, F. and Woodcock, M. (1996) Pittas, broadbills and asities. Pica Press, Sussex.

[2] BirdLife International (2001) Threatened birds of Asia: The BirdLife International red data book. BirdLife International, Cambridge.

[3] Kim, E.M. (2006) The distribution and breeding ecology of fairy pitta (pitta nympha) on Mt. Halla. Research Institute of Mt.Hallasan, Jeju.

[4] Kim, H.K. (1964) The ecology of fairy pitta. Bulletins of Korea Cultural Resarch Institute, 5, 235-240.

[5] Won, P.O. (1968) Animals in Hallasan, in ministry of culture and Public information. Report on the scientific survey on natural preserves of Mt. Hallasan and Hongdo Island, Ministry of Culture and Public Information, Seoul.

[6] Kim, E.M., Oh, H.S., Kim, S.B. and Kim, W.T. (2003) The distribution and habitat environment of fairy pitta (pitta nympha temminck \& Schlegel) on Jeju Island, Korea. Korean Journal of Ornithology, 10, 77-86.

[7] Lin, R.S., Yao, C.T. and Lee, P.F. (2007) The diet of fairy pitta pitta nympha nestling in Taiwan as revealed by videotaping. Zoological Studies, 46, 355-361.

[8] Kim, C.M., Park, C.R., Chung, Y.G., Son, S.G., Kim, C.S. and Kim, J. (2009) Sustainable forest management of warm-temperate forests. Korea Forest Research Institute, Jeju.

[9] Zar, J.H. (1984) Biostatistical analysis. Prentice-Hall Inc.,
New Jersey.

[10] R Development Core Team (2011) R: A language and environment for statistical computing. $\mathrm{R}$ Foundation for Statistical Computing, Vienna.

[11] Satchell, J.E. (1955) Some aspects of earthworm ecology, In: Kevan, D.K.Mc.E., Ed., Butterworths, Soil Zoology, London, 180-201.

[12] Na, Y.E., Lee, S.B., Han, M.S., Kim, S.G. and Choi, D.R. (2000) Soil properties influencing on earthworm habitation in upland. Korean Journal of Soil Zoology, 5, 165168.

[13] Cody, M.L. (1974) Competition and the structure of bird communities. Princeton University Press, New Jersey.

[14] Chung, S.H., Park, J.K., Kim, J.T. and Kim, B.W. (2004) Invertebrates. Korea Forest Research Institute, Seoul.

[15] Park, C.R., Lee, S.G., Byun, K.O., Kim, C.M., Chung, Y.G., Kim, E.M. and Jeong, S.B. (2008) An eco-guide book to the wildlife in Jeju experimental forests. Korea Forest Research Institute, Seoul.

[16] Naef-Daenzer, B. and Keller, L.F. (1999) The foraging performance of great and blue tits (Parus major and P. caeruleus) in relation to caterpillar development, and its consequences for nestling growth and fledgling weight. Journal of Animal Ecology, 68, 708-718. doi:10.1046/j.1365-2656.1999.00318.x

[17] Naef-Daenzer, L., Naef-Daenzer, B. and Nager, R.G. (2000) Prey selection and foraging performance of breeding Great Tits parus major in relation to food availability. Journal of Avian Biology, 31, 206-214. doi:10.1034/j.1600-048X.2000.310212.X

[18] Grieco, F. (2002) Time constraint on food choice in provisioning blue tits, parus caeruleus: The relationship between feeding rate and prey size. Animal Behaviour, 64, 517-526. doi:10.1006/anbe.2002.3073

[19] Knapton, R.W. (1984) Parental feeding of nestling nashville warblers: The effects of food type, brood-size, nestling age, and time of day. Wilson Bull, 96, 594-602.

[20] Van Horne, B. and Bader, A. (1990) Diet of nestling winter wrens in relationship to food availability. Condor, 92, 413-420. doi:10.2307/1368238

[21] Haggerty, T.M. (1992) Effects of nestling age and brood size on nestling care in the Bachman's Sparrow (Aimophila aestivalis). The American Midland Naturalist Journal, 128, 115-125. doi:10.2307/2426418

[22] Smetak, K.M., Johnson-Maynard, J.L. and Lloyd, J.E. (2007) Earthworm population density and diversity in different-aged urban systems. Applied Soil Ecology, 37, 161-168. doi:10.1016/j.apsoil.2007.06.004 